\title{
IMPACT OF ORNAMENTAL PLANTS IN THE ARCHITECTURE OF GREEN URBAN ENVIRONMENTS IN KOSOVO
}

\author{
Besnike Aliaj $^{1 *}$, Isuf Lushi ${ }^{1}$ \\ I"Faculty of Life and Environmental Sciences University "Ukshin Hoti” Prizren (UPZ), Kosovo; \\ *Corresponding Author Besnike Aliaj, e-mail: Besnike_aliaj@hotmail.com;
}

Received June 2019; Accepted August 2019; Published October 2019;

DOI: https://doi.org/10.31407/ijees9419

\begin{abstract}
The interest and demands of people for ornamental plants in our country grows more and more, due to the expansion of urban areas, and especially of big cities. Noise or high acoustic pollution from vehicle movements, noise and other obstacles and the physical and chemical pollution of the earth has removed man from nature by worsening his health and emotional and emotional state. Noise or high acoustic pollution from vehicle movements, noise and other obstacles and the physical and chemical pollution of the earth has removed man from nature by worsening his health and emotional and emotional state. Greening can not meet all human needs for aesthetic, health, etc. requirements, but it is always preferable to plant as many ornamental flowers as possible. In the last decade, the regulation of gardens in Kosovo also took an important step, and as a result, their role increased, especially in big cities such as: Prizren, Peja, Prishtina, etc. From our research we conclude that the impact of ornamental plants in the urban environment architecture in Kosovo is important, as $68 \%$ of the respondents stated with positive opinion and positive response, and $71 \%$ said that the architecture of the surfaces is very important in Kosovo, with regard to the survey of which cities of Kosovo devote most importance to ornamental flowers are citizens of Prizren, with $28 \%$ of respondents, with $44 \%$ of respondents think that landscape architecture is important for human health while $56 \%$ think it has an impact on the architecture of green urban environments. In our research $34 \%$ of respondents think that maintenance of gardens in green urban environments is difficult.
\end{abstract}

Keywords: Kosovo, ornamental plants, architecture, urban environments, garden. 